\section{"A gente vive em cima da corda bamba": experiência de profissionais da saúde que trabalham com o HIV/aids em uma área remota do Nordeste brasileiro}

\author{
"We live on the tightrope": the experience of health \\ professionals working with HIVIAIDS \\ in a remote area of Northeast Brazil
} "Vivimos sobre una cuerda floja": experiencia de
profesionales de salud que trabajan con VIH/SIDA
en una área remota del Nordeste brasileño
Thais Raquel Pires Tavares 1

Lucas Pereira de Melo 2

\title{
Resumo
}

Esta etnografia objetivou compreender a experiência de profissionais da saúde que trabalham em um Serviço de Atenção Especializada em HIV/aids num contexto de área remota, no Nordeste brasileiro. Para a coleta de dados, utilizaram-se observação participante e entrevista semiestruturada com sete profissionais que compunham a equipe do serviço estudado. Por meio da técnica de codificação temática, obtiveram-se três categorias: "eu não sabia nem o que era": aspectos do vir a ser profissional especializado em HIV/aids; "está todo mundo lá meio que escondido”: estratégias de enfrentamento à (in)visibilidade do status sorológico; $e$ "a gente vive em cima da corda bamba”: experiências no processo de trabalho. $O$ aspecto mais relevante deste estudo diz respeito à invisibilidade institucional do serviço como reflexo da atual configuração do dispositivo da aids no Brasil. Os resultados assinalaram algumas dificuldades próprias de serviços localizados em áreas remotas, notadamente a inexperiência dos profissionais e seu agravamento pela carência de educação permanente, necessidades infraestruturais, o lugar das ações de saúde em HIV/aids na agenda política local e a centralidade do fazer médico na organização do processo de trabalho. Destacou-se, ainda, a agência dos interlocutores na produção de estratégias de enfrentamento dessas dificuldades. Este estudo acrescenta ao ressaltar a dimensão local como um marcador social da diferença que modelava as experiências dos interlocutores, pois é ali onde as diretrizes e os princípios da política de saúde são performados por profissionais, gestores e usuários compondo materialidades diversas.

HIV; Síndrome de Imunodeficiência Adquirida; Pessoal de Saúde; Serviços de Saúde Rural

\author{
Correspondência \\ T. R. P. Tavares \\ Rua Augusto Monteiro 871A, Caicó, RN 59300-000, Brasil. \\ enfathais@outlook.com \\ 1 Universidade Federal do Rio Grande do Norte, Caicó, Brasil. \\ 2 Universidade de São Paulo, Ribeirão Preto, Brasil.
}




\section{Introdução}

Desde os anos 1980, a epidemia provocada pelo vírus da imunodeficiência humana/síndrome de imunodeficiência adquirida (HIV/aids) tem envolvido uma ampla mobilização da sociedade civil e de pesquisadores, trabalhadores e gestores da área da saúde na perspectiva de produzirem respostas efetivas e eficientes ao quadro geral de adoecimento, morte e estigmatização das populações afetadas pelo vírus. Nesse contexto, as respostas das políticas públicas nas arenas da saúde e social têm se constituído como um desafio para a saúde pública mundial mesmo depois de quase 40 anos de epidemia 1,2,3.

No Brasil, o perfil epidemiológico da epidemia de HIV/aids se caracteriza como multifacetado e em constantes transformações entre os diferentes grupos sociais e regiões 4,5,6, com destaque para o processo de interiorização da infecção ${ }^{7}$. Diante desse panorama, o presente estudo busca problematizar a experiência de profissionais da saúde que trabalham em um Serviço de Assistência Especializada em HIV/aids (SAE) num contexto de área remota no Nordeste brasileiro. No país, as questões relativas à atenção à saúde de populações que vivem em áreas remotas (incluindo os trabalhadores do setor) ganharam maior relevo com a implantação do Programa Mais Médicos, em 20138.

Tais questões suscitaram discussões sobre os critérios de definição e classificação dessas áreas, à medida que as taxonomias disponíveis (urbano, semirrural, rural, remoto, remoto rural) nem sempre abrangiam as realidades e contextos locais em sua complexidade 9 . Neste estudo, área remota é entendida como uma complexa experiência social e (inter)subjetiva dada por diversas formas de isolamento: geográfico; sociocultural; ambiental; além da dificuldade de acesso ao suporte e comunicação com outros profissionais (de saúde) e pela deficiência de infraestrutura, comunicação e recursos 10. Por essa perspectiva, aqui, a dimensão local não se coloca como uma limitação, mas como uma estratégia teórico-metodológica, compreendida como um marcador social da diferença que modela as experiências dos sujeitos que vivem e trabalham nessas regiões. Nesse sentido, tal dimensão foi apreendida como suscitadora de relações sociais, de moralidades e de formas de pensar e de operacionalizar a política norteada por códigos sociais próprios de contextos interioranos, o que não significa dizer que esses aspectos inexistam nos centros urbanos.

Nesses termos, um dos desafios postos ao Sistema Único de Saúde (SUS) é a necessidade de uma abordagem sensível aos contextos locais nos quais se produzem o cuidado das pessoas vivendo com HIV/aids (PVHA), uma vez que é ali onde as diretrizes e os princípios da política de saúde são performados por profissionais, gestores e usuários a compor materialidades diversas. Dessa forma, para além dos aspectos epidemiológicos, clínicos e organizacionais que permeiam o trabalho desses profissionais, observam-se lacunas na literatura especializada quanto às experiências construídas, compartilhadas e significadas por esses sujeitos no processo de trabalho, mediante uma perspectiva socioantropológica.

Tais aspectos mostram-se relevantes, pois as necessidades e preocupações específicas dos contextos de áreas remotas tendem a permanecer inauditas ou desconhecidas no nível macro ou nacional dos sistemas e políticas de saúde 9 . Além disso, a literatura tem chamado a atenção para os índices de estresse ocupacional entre profissionais que atuam nesses cenários $11 \mathrm{e}$ as peculiaridades do manejo do sigilo e da confidencialidade sobre a soropositividade em áreas remotas 12,13. Diante disso, teve-se como objetivo compreender a experiência de profissionais da saúde que trabalham em um SAE, num contexto de área remota no Nordeste brasileiro.

\section{Metodologia}

Trata-se de uma pesquisa social, cujo referencial metodológico foi a etnografia. No contexto dos serviços de saúde, a etnografia tem permitido o desvelamento das múltiplas configurações dos modelos de atenção, bem como a diversidade de concepções, de sentidos, de práticas e de experiências que atravessam os estados de saúde e de adoecimento, incluindo a produção do cuidado em saúde 14 .

O trabalho de campo foi conduzido no período de julho a dezembro de 2017 num SAE localizado em um município do sertão do Rio Grande do Norte, Brasil. O Estado possuía, à época da pesquisa, 15 serviços dessa modalidade, dos quais cinco estavam sediados em municípios do interior. A escolha do 
serviço se justificou por sua abrangência regional no atendimento ambulatorial às PVHA e a pessoas com outras doenças infecciosas (é referência para 25 municípios de pequeno e médio porte) e por possuir equipe multiprofissional completa.

O município está localizado em área remota porque se situa a $280 \mathrm{~km}$ de distância da capital (Natal), em uma região do sertão nordestino historicamente marcada pela ocorrência das secas, $o$ que leva à vulnerabilidade ambiental, climática e à insustentabilidade da economia. Isso se reflete na ausência de suporte técnico-científico de outros profissionais e dos serviços de saúde que eram referência em infectologia. Os dois hospitais-referência para infectologia ficavam nos municípios de Mossoró (a 186km) e em Natal. No que tange à infraestrutura, destacam-se as condições precárias do próprio prédio onde o SAE funcionava até 2017. Além disso, os interlocutores reivindicavam melhores condições de trabalho e apontavam problemas decorrentes do uso inadequado dos recursos financeiros.

Esse serviço foi criado em 2010 e contava apenas com um médico (não era infectologista) e uma enfermeira que realizavam atendimentos pontuais. Apenas em 2012, o serviço sofreu uma reestruturação que lhe conferiu a configuração atual. A equipe ("emprestada" de outros equipamentos da rede de saúde) passou a ser composta por servidores públicos municipais, com exceção da médica que era contratada por processo seletivo, vinculados a equipes de outros serviços, que eram cedidos dois dias por semana para atuação no SAE. Essa equipe participou de um curso de capacitação oferecido pela Secretaria Estadual de Saúde sobre o trabalho no SAE, durante os primeiros nove meses de funcionamento do SAE. Segundo relato dos interlocutores, esse foi um dos únicos momentos formativos.

Em abril de 2017, momento da primeira visita ao serviço, ele funcionava na policlínica do município, ocupando duas pequenas salas no final de um dos corredores. Porém, estava em andamento a mudança para uma estrutura maior e mais "discreta" no prédio do hospital-maternidade. Apesar das melhorias infraestruturais do novo local, as instalações físicas ainda eram avaliadas pelos profissionais como insuficientes. Parte dessa problemática resultava da gestão do serviço, pois, mesmo atendendo à população dos 25 municípios da região de saúde, contava somente com os repasses do Programa Estadual de IST, AIDS e Hepatites Virais e com o suporte da secretaria municipal de saúde local para recursos humanos, insumos e infraestrutura.

Durante o trabalho de campo, contava-se com uma equipe multiprofissional composta por sete profissionais: uma médica infectologista, um farmacêutico, uma psicóloga, uma assistente social, uma nutricionista e dois enfermeiros (um deles exercia a coordenação da equipe). Todos aceitaram participar do estudo de forma voluntária, após serem convidados pessoalmente pela pesquisadora (primeira autora). Os critérios de inclusão foram: ser funcionários efetivamente ligados ao serviço, independentemente do tempo de trabalho e aceitar participar voluntariamente da pesquisa por meio do consentimento livre e esclarecido.

A imersão da pesquisadora em campo se deu após aprovação do projeto pelo Comitê de Ética em Pesquisa da Faculdade de Ciências da Saúde do Trairí da Universidade Federal do Rio Grande do Norte, conforme Resolução no 510/2016 do Conselho Nacional de Saúde. A entrada em campo foi facilitada por dois interlocutores (farmacêutico e nutricionista) que atuavam no Núcleo de Apoio à Saúde da Família e já conheciam a pesquisadora, visto que ela atuava como residente de saúde coletiva em uma unidade básica de saúde do município. A partir disso, a pesquisadora pôde participar como observadora nas consultas individuais, na dispensação de medicamentos antirretrovirais, em ações de educação em saúde, no aconselhamento e na testagem rápida para HIV, sífilis e hepatites virais. Esses atendimentos se realizavam de terça à quinta-feira, de acordo com a escala de cada profissional. $\mathrm{Na}$ quinta-feira, todos estavam presentes, pois era o dia do atendimento médico. Em razão da presença da pesquisadora nos dias de atendimento, logo ela foi deixando de ser uma pessoa "estranha" à equipe e aos usuários, o que lhe permitiu aprofundar suas incursões em campo.

À medida que se tornava "conhecida", a pesquisadora pôde observar as consultas individuais, as conversas informais dos profissionais durante os lanches e o café, conversar com usuários na sala de espera, acompanhar ações externas ao SAE e participar de situações de confraternização da equipe. Em alguns momentos, era acionada sua condição de pesquisadora. Em outros, sua formação em saúde facilitava alguns engajamentos, notadamente na organização de ações de saúde coletiva. Em ambas as situações, a pesquisadora sempre se mostrou disponível para observar, participar, colaborar e, sobre- 
tudo, a aprender com os interlocutores sobre seus saberes, práticas e pontos de vista. As informações e impressões coletadas por meio da observação participante foram registradas em diário de campo.

Decorridos dois meses do trabalho de campo, a pesquisadora iniciou os convites aos interlocutores (profissionais da equipe) para entrevistas individuais semiestruturadas. Foram realizadas sete, no total. Os locais e horários foram previamente agendados e escolhidos pelos interlocutores. As entrevistas foram conduzidas apenas pela primeira autora, tiveram duração média de 90 minutos e foram norteadas por um roteiro com tópicos-guia semiestruturados previamente testado. As entrevistas foram registradas em áudio e, posteriormente, transcritas.

A análise dos dados ocorreu concomitantemente à coleta. Utilizou-se a técnica de codificação temática para análise do material obtido, por meio da qual foi possível criar um sistema de categorias que abarcasse os conceitos e códigos presentes nas falas das pessoas entrevistadas 15. Na fase final da análise, foi apresentada uma versão preliminar dos dados já categorizados aos interlocutores e a membros de um grupo de pesquisa a que os autores estavam vinculados com o objetivo de realizar a validação e a devolutiva dos resultados. Essas situações foram estruturadas com base nas experiências relatadas por outros autores 16,17 e suscitaram discussões que permitiram o aprofundamento da análise, a validação e a avaliação dos resultados da pesquisa. As categorias preliminares foram validadas sem modificações pelos interlocutores, porém incluíram-se aspectos apontados por eles em cada categoria, o que colaborou para tornar a análise e a interpretação dos dados mais aprofundadas. Após análise e interpretação do material empírico, obtiveram-se três categorias temáticas. Os nomes dos interlocutores são fictícios. Para termos êmicos, utilizaram-se aspas simples.

\section{Resultados e discussão}

\section{"Eu não sabia nem o que era": aspectos do vir a ser profissional especializado em HIV/aids}

Esta categoria expressa a experiência dos interlocutores em compor a equipe de um SAE, cuja atuação profissional requeria competências específicas e para as quais, em seus entendimentos, não foram preparados adequadamente. Dessa maneira, os dados etnográficos evidenciaram as estratégias e os agenciamentos produzidos por esses sujeitos com vistas ao aprimoramento profissional, notadamente os aprendizados socializados na própria prática cotidiana. Além disso, enfatiza-se a maneira como esses profissionais têm construído, de maneira processual, suas expertises em torno do HIV/aids.

A maneira como o SAE foi criado apresenta uma relação direta com a dimensão processual do "vir a ser especialista”. De acordo com os interlocutores, no momento de estruturação da nova equipe, a gestão realizou "convites" aos profissionais que já compunham outros serviços do município. O ingresso em um novo serviço e em outra área da assistência foi entendido pelos profissionais como um desafio que, diante da falta de especialização ou experiência prévia, permitia-lhes o encontro com uma nova práxis e a possibilidade de aprimorar e fortalecer expertises: "eu vim trabalhar aqui porque o serviço precisava de um farmacêutico e foi a chance de começar uma coisa diferente" (Tomaz, farmacêutico do serviço há quatro anos); "eu não tinha muita experiência, tinha pouco conhecimento, mas iria acrescentar para eles o pouco que eu sabia e para aprender também" (Flávia, nutricionista do serviço há três anos); "quando me convidaram, eu pensei: eu não entendo nada de infectologia, mas eu vou, é um aprendizado. E fui com a cara e a coragem" (Pedro, enfermeiro do serviço há quatro anos).

Contudo, diante da necessidade de aperfeiçoamento profissional e do fato de trabalharem em área remota, o compartilhamento de vivências e conhecimentos entre pares estava restrito aos contatos dentro da própria equipe: "a gente tem uma parceria muito grande, a gente pede ajuda um ao outro, troca experiências e trabalha com um só objetivo: a melhoria" (Pedro). O que se constatou em campo é que nem sempre essa "ajuda" era suficiente. Durante o trabalho de campo, foram acompanhados os casos de algumas gestantes que viviam com HIV/aids e/ou desenvolviam outras infecções como toxoplasmose e citomegalovirose. Nessas situações, cabia à assistente social telefonar para um serviço na região metropolitana de Natal para elucidar dúvidas e agendar a primeira consulta de pré-natal. Nos casos acompanhados, após referenciar para o outro serviço, os interlocutores perdiam contato com a gestante, que só retornava após o parto, sem contrarreferência para dar seguimento ao seu tratamento e ao do recém-nascido. Em outras situações, ligava-se para hospitais de referência apenas para obter 
informações e orientações sobre casos específicos. Algumas vezes, obtinha-se êxito; outras, pedia-se para retornar a ligação depois, já que a pessoa responsável não estava no momento. Em todo caso, essa situação evidenciava a inexistência de mecanismos institucionalizados de referência e contrarreferência, fato que dificultava a comunicação entre os serviços e o atendimento integral às PVHA.

Experiências semelhantes têm sido relatadas em estudos conduzidos em grandes centros urbanos, como São Paulo e Rio de Janeiro 18,19: ingressar no SAE oriundos de outros serviços; ausência de experiências prévias e conhecimento sobre o tratamento de PVHA; necessidade de vencer barreiras pessoais (preconceitos e diferenças, por exemplo) para executar o trabalho; oferta reduzida de treinamentos teórico-práticos; e a aprendizagem pela prática e pela observação dos pares. No contexto investigado, essas situações eram amplificadas porque a distância dos centros de referência, a ausência de suporte técnico-científico (matriciamento) e de educação permanente agravavam a sensação de isolamento: "a gente já está cobrando ao serviço de aids do Estado para que faça outras capacitações porque a cada dia é um conhecimento novo. A gente precisa se capacitar, trocar experiência com profissionais de grandes centros" (Pedro). Dificuldades relativas à educação permanente em saúde também foram relatadas por obstetrizes que atuavam em áreas remotas e rurais da Nova Zelândia, por conta da ausência e da distância de suporte por pares 9 .

Para enfrentar essa problemática, os interlocutores desenvolviam "autocapacitações”, uma vez que atuavam num campo com constantes atualizações de rotinas e protocolos. A "autocapacitação" dizia respeito às estratégias individuais e coletivas; estas últimas próprias da equipe/serviço que permitia aos profissionais "atualizações" em matérias de HIV/aids: "como não há educação permanente, eu sempre estou entrando no site do Ministério, no iAIDS..." (Tomaz); "a gente não tem capacitações, mas a gente vai se autocapacitando com leituras, com a experiência no serviço, com o contato com outros profissionais" (Amélia, assistente social do serviço há dois anos e meio). Apesar dos esforços para fornecer um bom atendimento com e apesar das dificuldades e a motivação para fazer o serviço funcionar com qualidade, os interlocutores pareciam ainda não se sentirem preparados suficientemente para desenvolver um trabalho qualificado: "não sei onde está o defeito ou a fragilidade, mas acho que é por não termos acesso a essas capacitações, nem a discussões mais profundas sobre a temática. Isso dificulta nosso trabalho. Então, profissionalmente, eu não sou satisfeita com a minha atuação, tem muitas limitações" (Amélia).

Tais dificuldades também apontam para fragilidades no ensino de graduação. Estudo evidenciou que os componentes curriculares desses cursos não permitem ao estudante desenvolver competências e habilidades necessárias para cuidar de PVHA 20. Na análise deste estudo, essa invisibilização do HIV/ aids na formação em saúde faz parte de um cenário maior caracterizado pela restrição contemporânea dos discursos sobre a doença em diversos setores sociais e culturais brasileiros 21. Quando observados por intermédio da experiência dos interlocutores deste estudo, tal problemática ganha sentidos políticos, visto que desvela as fragilidades das estratégias governamentais (nacional e internacionais) que propagam o "fim da aids" 22,23. Essas iniciativas têm sido questionadas frente ao aumento das taxas de incidência tanto da infecção pelo HIV quanto da aids 6,24, do subfinanciamento do SUS, dos entraves colocados pela propriedade intelectual ao acesso à TARV de qualidade, das dificuldades financeiras e jurídicas das organizações da sociedade civil que trabalham com prevenção e educação em HIV/ aids, e do recrudescimento da moral conservadora no país e seus impactos nas discussões de gênero, sexualidade e direitos humanos, na formulação de políticas e na produção legislativa 25 .

\section{"Está todo mundo lá meio que escondido": estratégias de enfrentamento da (in)visibilidade do status sorológico}

Esta categoria aborda a forma como a manutenção do segredo sobre a soropositividade dos usuários em um contexto de área remota implicava a produção de uma invisibilidade institucional do serviço. Partiu-se do pressuposto de que tal invisibilidade era tributária dos processos sociais de estigma e discriminação das PVHA na sociedade mais ampla. Com isso, pretende-se destacar as peculiaridades do manejo do sigilo e da confidencialidade sobre a soropositividade em áreas remotas, o que não significa que seja um fenômeno exclusivo desses lugares. $O$ foco aqui é analisar como o lugar - áreas remotas - pode suscitar relações sociais, moralidades, códigos sociais e fronteiras entre a vida pública e a privada diferentes daquelas estabelecidas em grandes centros urbanos. 
A partir dos anos 2000, o cenário da epidemia de HIV/aids no Brasil muda significativamente com a cronificação da infecção pelo HIV em decorrência da distribuição gratuita e universal da terapia antirretroviral (TARV) e dos avanços biotecnológicos desses fármacos. É nesse panorama que o viver com HIV/aids se configurou como uma "doença segredo" 21, pois o tratamento possibilitou qualidade e ampliação da expectativa de vida e facultou à PVHA vivenciar a condição na intimidade de seu corpo, fazendo do segredo e do silêncio elementos em torno dos quais se constroem sua experiência, resultando na invisibilidade social das PVHA 26. Ou seja, o segredo/silêncio permitiu às PVHA se livrarem de alguns estigmas da "aids de antes" (doença fatal), em um movimento contínuo e intenso de positivação desses sujeitos 27 .

Esses processos macrossociais se refletiram no nível local, interseccionando-se com aspectos próprios da organização social e da história do município cenário deste estudo: modos de vida e de sociabilidade próprios das "cidades de interior", as relações sociais e de parentesco se davam mais entre pessoas e não tanto entre indivíduos e onde essas pessoas tendiam a se conhecer, borrando assim o anonimato comum nos grandes centros urbanos 28 . Dessa maneira, as relações sociais naquela cidade se construíam, em geral, com base em vínculos familiares e de amizades, gerando ligações de afetividade e compadrio. Tendo em vista esses aspectos, a literatura tem apontado evidências de que, em cidades pequenas e em áreas rurais, a experiência de perda de privacidade - especialmente quando envolve o HIV/aids - é aumentada 12,13,29.

Nesse contexto, surgiam os desafios quanto à proteção do sigilo e da confidencialidade sobre a soropositividade, o que impunha aos profissionais a responsabilidade de produzirem estratégias de enfretamento. Em 2017, por ocasião da mudança para a atual sede do SAE, ficaram evidentes as preocupações em evitar a vinculação do prédio ao HIV/aids, o que, na visão dos interlocutores, estigmatizaria o serviço: "lá [no local anterior] não tinha muito sigilo, porque ficava todo mundo numa sala só. aqui está ótimo, mas temos medo de dizerem: ali é só o pessoal da aids" (Joana, médica infectologista do serviço há três anos). Em estudo etnográfico desenvolvido em três clínicas especializadas em HIV/aids, no Canadá, que atendiam a pessoas residentes em áreas urbanas, suburbanas e rurais, os profissionais frisaram a existência de uma economia das relações espaciais dentro das clínicas, por parte das PVHA, dada a possibilidade de serem reconhecidas por "alguém que conhece alguém que conhece alguém". Diante disso, os participantes da pesquisa criavam estratégias como consultas e exames com hora marcada, existência de vários espaços para espera de atendimentos, de maneira que se evitassem encontros e olhares denunciativos 13 .

Essas situações se refletiram nas primeiras interações da pesquisadora em campo, quando andar por esse "terreno de silêncios e segredos" foi extremamente desafiador. Era inevitável perceber nos gestos dos usuários a tensão diante da presença de uma pessoa "de fora". Com o tempo, esse "terreno" foi se modificando. A pesquisadora passou a ser vista como alguém (quase) "de dentro", o que permitiu a produção de relações e sociabilidades. A essa altura, os usuários começaram a fazer conversas sobre direitos previdenciários, experiências de tratamento e outros assuntos não relacionados ao HIV/aids na sala de espera. Esses momentos rompiam com o silêncio, a impessoalidade e a evitação de olhares comuns naquele espaço.

Os profissionais também desenvolviam e aprimoravam outras estratégias para a proteção do sigilo. Além de considerarem importante a baixa rotatividade de profissionais na equipe, os interlocutores relataram uma série de comportamentos e normas que compunham um código de ética profissional nativo: "a gente tenta não conversar na frente dos outros usuários. Deixamos para conversar na nossa sala, porque é mais reservada" (Pedro); "muitas pessoas chegam e perguntam [se as pessoas que estavam lá viviam com HIV/aids], mas a gente não diz, porque sabe que isso é errado. E assim vamos dando nossos pulinhos e conseguindo disfarçar" (Tomaz). Além desses "pulos", eram acionadas outras estratégias, tais como: guardar os prontuários em armário com chave e em sala reservada; dispensação de medicamentos em embalagens alternativas; o "jogo de cintura" ao encontrar os usuários em outros lugares e não dar "pistas" de onde se conheceram; a entrega dos resultados de exames no laboratório regional exclusivamente aos profissionais do serviço. Essas e outras ações eram entendidas como uma primazia da prática profissional: "é uma prioridade nossa manter o sigilo a que o usuário tem direito. O principal é a gente, enquanto profissional, ser ético e saber da nossa responsabilidade em relação a isso" (Amélia).

Cumpre destacar que a proteção do sigilo e da confidencialidade requer não só atenção de princípios éticos de cada profissão e da legislação que protege os direitos das PVHA, mas, sobretudo, a 
criação de formas organizativas do processo de trabalho que considerem esses aspectos. As etnografias realizadas em outros contextos desvelaram que essas práticas foram observadas 12,13, assim como entre os interlocutores deste estudo. Apesar disso, em serviço do interior do Mato Grosso do Sul foram relatadas situações que favoreciam a negligência da manutenção do sigilo e a exposição da privacidade dos usuários do serviço (inclusive de uma das pesquisadoras) em decorrência da dificuldade de anonimato e do tênue limite entre a privacidade e o convívio social, característicos de cidades do interior 12. Por outro lado, há um dilema ético experienciado pelos profissionais, conforme relatado por Kaposy et al. 13, à proporção que o dever de proteger a confidencialidade pode implicar a evitação do confronto e da mitigação do estigma e da discriminação das PVHA. Na realidade estudada, verificou-se que tal dilema resultou, também, numa invisibilidade institucional, dado que o SAE ocupava um lugar marginal na agenda política da saúde local e na sociedade em geral. Como expressou Cássia (psicóloga do serviço há quatro anos), "está todo mundo lá meio que escondido".

\section{"A gente vive em cima da corda bamba": experiências no processo de trabalho}

Esta categoria discute as implicações da configuração do serviço e sua relação com a gestão local para a organização do processo de trabalho. A questão em torno dos processos de trabalho no presente contexto também passa pela forma como o serviço foi criado e constituído. Diante dessa realidade, surgiram inicialmente duas problemáticas: a fragilidade da organização do processo de trabalho, motivada pela falta de uma equipe específica que faça o serviço funcionar de maneira integral e efetiva; e a centralidade assumida pelo atendimento médico na lógica organizacional do serviço.

Na visão dos interlocutores, a questão do "empréstimo" dos profissionais se tornou uma problemática porque gerava sentimentos de incerteza e insegurança, bem como dificuldade para o funcionamento adequado do serviço, como destacou Amélia: "não existe uma equipe do SAE propriamente dita. Nós não fomos aprovados em concurso ou processo seletivo para trabalhar aqui. A gente vive em cima da corda bamba, então não tem como ter boas expectativas. A gente vive com essa insegurança". Os vínculos de trabalho precários interferiam tanto na prestação de uma assistência qualificada quanto na ampliação do acesso, além de interferir sobre a própria motivação e expectativas sobre a permanência no serviço. Esses aspectos reforçavam as noções de um cuidado que é produzido "na corda bamba", em que se faz o possível com e apesar dos entraves, já que a efetividade e a disponibilidade do cuidado prestado dependia dos (re)arranjos produzidos pela equipe com seus outros locais de trabalho: "dentro das dificuldades, a gente ainda toca o serviço pra frente" (Joana). Esses elementos organizacionais produziam lacunas na assistência à saúde prestada, particularmente porque, na falta de uma equipe exclusiva, o serviço funcionava em horário reduzido e com equipe reduzida na maioria dos dias, diferentemente, portanto, da maioria dos serviços especializados em HIV/aids no Brasil, sobretudo em grandes centros urbanos, que permanecem abertos ao público cinco ou mais dias da semana, por oito ou mais horas ao dia 30.

Outra necessidade apontada pelos interlocutores como "urgente" era a oferta de educação permanente em saúde, conforme discutido anteriormente. Esses processos formativos têm sido salientados na literatura como imprescindíveis na mobilização subjetiva do trabalhador, permitindo a este a capacidade de analisar e intervir em suas realidades, produzindo práticas inovadoras e democráticas 31 . $\mathrm{Na}$ avaliação deste estudo, tal carência de educação permanente em saúde era, a um só tempo, produtora e produto da invisibilidade institucional discutida acima, estando, assim, entrelaçada nessa "corda bamba" que marcava a experiência de trabalho dos interlocutores.

A terceira problemática desvelada foi a centralidade que o atendimento médico assumia na rotina do serviço. Numa manhã de quinta-feira, quando a pesquisadora chegou para mais um dia de trabalho de campo, percebeu que, antes mesmo de abrir as portas do serviço, já havia usuários garantindo seu lugar na fila, pois os atendimentos médicos aconteciam por ordem de chegada. Conforme os profissionais iam chegando, abriam as portas e iniciavam o "preparo" (retirada de prontuário, aferição de pressão arterial, pesagem) para as consultas médicas. À medida que outros membros da equipe chegavam, iam se juntando ao trabalho em andamento (a médica costumava ser a última a chegar). Essa temporalidade era percebida pelos usuários do serviço com preocupação, sobretudo para os que residiam em outros municípios ou na zona rural, tendo em vista seus compromissos e rotinas diárias fora dali. Os profissionais, por sua vez, tentavam gerenciar esses tempos que, em geral, eram tributários do tempo da médica. Por isso, a quinta-feira era o dia em que a equipe precisava estar completa 
no serviço: "não estamos juntos todos os dias, mas pelo menos na quinta-feira [dia de atendimento médico] todo mundo está junto" (Cássia).

Conforme se observa, o trabalho da médica se colocava como o ordenador e regulador do processo de trabalho da equipe se contrapondo, então, àquilo que é preconizado pela política de saúde - o trabalho "interdisciplinar" 32 que, numa leitura mais atual, se traduziria como um trabalho colaborativo e interprofissional 33. Sendo assim, esse processo de trabalho passava a ser, na experiência dos interlocutores de outras categorias profissionais (que não a medicina), dependente de encaminhamentos médicos ou da procura espontânea do usuário: "o trabalho aqui se resume assim: o usuário chega ao serviço, é atendido pela médica e se ele trouxer alguma demanda, poderá chegar ao serviço social, à nutrição. Mas a gente não tem como procurar a demanda no usuário. Só se ele trouxer" (Amélia). Vale dizer, não havia um cardápio de ofertas de serviços especializados, como consultas individuais com agenda aberta, para as demais especialidades, exceto a medicina.

Assim, o esforço empreendido pela equipe para organizar o atendimento médico é reconhecido como produtor de uma lacuna no cuidado integral às PVHA: "por se concentrar somente na quinta-feira [o atendimento da médica], o grande potencial da equipe, que poderia realizar essas outras ações, fica perdido" (Tomaz). Além disso, na dinâmica veloz em que acontecia o trabalho não restava espaço para discussões de caso, reuniões de equipe ou elaboração de projetos terapêuticos singulares. Em que pese a "urgência" de educação permanente em saúde relatada pelos interlocutores, os dados demonstram a necessidade de construção e institucionalização de espaços dialógicos, em que as questões relativas ao trabalho possam ser problematizadas, debatidas, negociadas, a fim de que não resultem em imobilismo, impotência e acomodação 31. Além disso, nesses momentos podem ser trabalhados os aspectos concernentes aos valores, às crenças, às práticas institucionais e os padrões de sociabilidade locais 12 .

De acordo com o entendimento dos interlocutores, somavam-se a essas questões a necessidade de uma coordenação mais presente e que atuasse de forma dialógica no enfrentamento conjunto das dificuldades já elencadas aqui. Do mesmo modo, os diversos entraves burocráticos na rede de assistência, aliados à falta de uma política municipal voltada ao HIV/aids, contribuíam para a perenidade de barreiras que obstam, no serviço, arranjos organizacionais mais democráticos e mais comprometidos com a vida das pessoas (profissionais e usuários).

\section{Considerações finais}

A análise do material empírico, associada ao referencial teórico-metodológico, permitiu a compreensão das diversas nuances implicadas na experiência de profissionais da saúde que trabalham em um SAE num contexto de área remota no Nordeste brasileiro. O estudo apreendeu as fragilidades de uma equipe "emprestada", sem experiências anteriores com a assistência em HIV/aids, que precisou e precisa aprender com e na prática como se deve manejar os conflitos decorrentes do lugar de invisibilidade que o serviço ocupa nas políticas de saúde locorregionais. Esses aspectos ganharam relevo quando foram consideradas as características de "cidade do interior" que modelavam a experiência de profissionais e usuários. Ao mesmo tempo, destacou-se a questão da organização dos processos de trabalho que ainda operava numa lógica médica centrada, evidenciando a necessidade de estimular a construção e institucionalização de espaços dialógicos que permitam refletir sobre as questões que emergem no trabalho em saúde com PVHA.

Além disso, a oferta de apoio institucional e de educação permanente em saúde pareceram ser as estratégias mais eficazes na produção das reflexões necessárias para se repensar a prática e se produzirem novas configurações na dinâmica assistencial. Para tanto, é preciso estabelecer uma maior aproximação com a gestão para a resolução de conflitos e demandas de forma participativa e dialógica. Esse é um movimento de reconhecimento, fortalecimento e valorização do profissional que contribui não só para a motivação no trabalho, mas para a produção de um profissional crítico e reflexivo, capaz de reorganizar seus processos de trabalho e contribuir para a prestação de uma assistência qualificada.

Por fim, espera-se que os resultados deste estudo possam estimular reflexões em torno da prática profissional nos serviços especializados em HIV/aids em contextos de área remota e da formulação de políticas públicas que tenham em conta as peculiaridades desses contextos, considerando, inclusive, a experiência brasileira acumulada por meio das ações como telemedicina, telessaúde, educação a 
distância, equipes de matriciamento, programas de tutoria e de supervisão e outras estratégias empregadas, por exemplo, no âmbito do Programa Mais Médicos. Ações dessa natureza poderão contribuir para a mitigação das desigualdades sociais em saúde, notadamente quando o foco se volta a esses muitos brasis profundos, conforme se quis evidenciar nesta investigação.

\section{Colaboradores}

T. R. P. Tavares foi responsável pela concepção do projeto, redação, revisão e finalização do artigo. L. P. Melo orientou a elaboração do projeto, redação, revisão e finalização do artigo.

\section{Agradecimentos}

Aos membros do Laboratório de Pesquisas Sociais em Medicina e Saúde, da Universidade Federal do Rio Grande do Norte.

\section{Referências}

1. Barros SG, Vieira-da-Silva LM. A gênese da política de luta contra a AIDS e o Espaço AIDS no Brasil (1981-1989). Rev Saúde Pública 2016; 50:43.

2. Mendonça PME, Alves MA, Campos LC. Empreendedorismo institucional na emergência do campo de políticas públicas em HIV/AIDS no Brasil. RAE-Eletrônica 2010; 9(1). http:// www.rae.com.br/eletronica/index.cfm?Fuse Action $=$ Artigo $\&$ ID $=5590 \&$ Secao $=$ ARTIGOS $\&$ Volume $=9 \&$ Numero $=1 \&$ Ano $=2010$.

3. Barros SG, Vieira-da-Silva LM. A terapia antirretroviral combinada, a política de controle da AIDS e as transformações do Espaço AIDS no Brasil dos anos 1990. Saúde Debate 2017; 41 (n.spe 3):114-28.

4. Guimarães MDC, Carneiro M, Abreu DMX, França EB. Mortalidade por HIV/AIDS no Brasil, 2000-2015: motivos para preocupação?. Rev Bras Epidemiol 2017; 20 Suppl 1:182-90.

5. Granjeiro A, Escuder MML, Castilho EA. Magnitude e tendência da epidemia de AIDS em municípios Brasileiros de 2002-2006. Rev Saúde Pública 2010; 44:430-41.

6. Ministério da Saúde. Boletim Epidemiológico AIDS e IST 2017; Ano V, n. 1.

7. Sousa AIA, Pinto Júnior VL. Análise espacial e temporal dos casos de AIDS no Brasil em 1996-2011: áreas de risco aumentado ao longo do tempo. Epidemiol Serv Saúde 2016; $25: 467-76$
8. Secretaria de Gestão do Trabalho e da Educação na Saúde, Ministério da Saúde. Programa Mais Médicos - dois anos: mais saúde para os brasileiros. Brasília: Ministério da Saúde; 2015.

9. Crowther S. Providing rural and remote rural midwifery care: an 'expensive hobby'. New Zealand College of Midwives Journal 2016; 52:26-34.

10. Malone G, Cliffe C; CRANA plus. Framework for remote practice (version 2). https://crana. org.au/files/pdfs/Framework_Remote_Prac tice_Version_2_June_2013.pdf (acessado em 18/Mar/2018).

11. Opie T, Dollard M, Lenthall S, Wakerman J, Dunn S, Knight S, et al. Levels of occupational stress in the remote area nursing workforce. Aust J Rural Health 2010; 18:235-41.

12. Bellenzani R, Mendes RF. Sigilo na atenção em DST/AIDS: do consultório aos processos organizacionais. Polis e Psique 2011; 1:140-65.

13. Kaposy C, Greenspan NR, Marshall Z, Allison J, Marshall S, Kitson C. Clinical ethics issues in HIV care in Canada: an institutional ethnographic study. BMC Med Ethics 2017; 18:9.

14. Ferreira J, Fleischer S, organizadores. Etnografias em serviços de saúde. Rio de Janeiro: Garamond; 2014.

15. Flick U. Introdução à pesquisa qualitativa. $3 \underline{a}$ Ed. Porto Editora Alegre: Editora Artmed; 2009. 
16. Furtado JP, Campos RO. Participação, produção de conhecimento e pesquisa avaliativa: a inserção de diferentes atores em uma investigação em saúde mental. Cad Saúde Pública 2008; 24:2671-80.

17. Campos RO. Fale com eles! o trabalho interpretativo e a produção de consenso na pesquisa qualitativa em saúde: inovações a partir de desenhos participativos. Physis (Rio J.) 2011; 21:1269-86.

18. Mora C, Monteiro S, Moreira COF. Education, practices and paths of counselors at HIV testing centers in Rio de Janeiro, Brazil. Interface (Botucatu, Online) 2015; 19:1145-56.

19. Silva NEK, Oliveira LA, Figueiredo WS, Landroni MAS, Waldman CCS, Ayres JRCM. Limites do trabalho multiprofissional: estudo de caso dos centros de referência para DST/AIDS. Rev Saúde Pública 2002; 36(4 Suppl):108-16.

20. Moraes EEA, Silva ICS, Freitas RDS, Medeiros Júnior A, Vasconcelos CM, Freitas MR. Professional training for ethical and comprehensive care of patients living with HIV/AIDS. MedEdPublish 2018; 7:38.

21. Inácio EC. Carga zerada: HIV/AIDS, discurso, desgaste, cultura. Via Atlântica 2016; 29:479505.

22. Grangeiro A, Castanheira ER, Nemes MIB. A re-emergência da epidemia de AIDS no Brasil: desafios e perspectivas para o seu enfrentamento. Interface (Botucatu, Online) 2015; 19:5-8.

23. Kenworthy N, Thomann M, Parker R. From a global crisis to the 'end of AIDS': new epidemics of signification. Glob Public Health 2018; 13:960-71.

24. Kerr L, Kendall C, Guimarães MDC, Mota RS, Veras MA, Dourado I, et al. HIV prevalence among men who have sex with men in Brazil: results of the 2 nd national survey using respondent-driven sampling. Medicine (Baltimore) 2018; 97(1S Suppl 1):S9-S15.
25. Basthi A, Parker R, Terto Jr. V. Mito vs realidade: sobre a resposta brasileira à epidemia de HIV e AIDS em 2016. Rio de Janeiro: Associação Brasileira Interdisciplinar de AIDS; 2016.

26. Melo LP. Por que nos tornaram crônicos? O discurso da cronicidade na atual configuração do dispositivo da AIDS no Brasil. In: Anais da II Reunião de Antropologia da Saúde. Brasília: Instituto de Ciências Sociais, Universidade de Brasília; 2018. p. 428-39.

27. Cunha CC. Os muitos reveses de uma "sexualidade soropositiva": o caso dos jovens vivendo com HIV/AIDS. Sex Salud Soc (Rio J.) 2012; 10:70-99.

28. Simmel G. A metrópole e a vida mental. In: Velho OG, organizador. O fenômeno urbano. 2a Ed. Rio de Janeiro: Jorge Zahar Editores; 1973. p. 11-25.

29. Goldstein DE. Once upon a virus: AIDS legends and vernacular risk perception. Logan: Utah State University Press; 2004.

30. Nemes MIB, Alencar TMD, Basso CR, Castanheira ELR, Melchior R, Alves MTSSB, et al. Avaliação de serviços de assistência ambulatorial em aids, Brasil: estudo comparativo 2001/2007. Rev Saúde Pública 2013; 47:13746.

31. Oliveira LA, Landroni MÂS, Silva NEK, Ayres JRCM. Humanização e cuidado: a experiência da equipe de um serviço de DST/AIDS no município de São Paulo. Ciênc Saúde Coletiva 2005; 10:689-98.

32. Departamento de DST, AIDS e Hepatites Virais, Ministério da Saúde. Política Brasileira de enfrentamento da AIDS: resultados, avanços e perspectivas. Brasília: Ministério da Saúde; 2012.

33. D'Amour D, Oandasan I. Interprofessionality as the field of interprofessional practice and interprofessional education: an emerging concept. J Interprof Care 2005; 19 Suppl 1:8-20. 
Abstract

This ethnographic study aimed to understand the experience of health professionals working in a Specialized Service for HIV/AIDS Care in a remote area of Northeast Brazil. Data collection used participant observation and a semi-structured interview with seven professionals in the health care team. The thematic coding technique yielded three categories: "I didn't even know what it was": aspects of becoming a specialist in HIV/AIDS; "They're all out there, kind of hidden": strategies for dealing with the (in)visibility of serological status; and "We live on the tightrope": experiences in the work process. The study's most relevant aspect was the service's institutional invisibility as a result of the current configuration of the AIDS structure in Brazil. The results revealed several difficulties that are typical of services located in remote areas, especially the health professionals' lack of experience, aggravated by the lack of continuing education, unmet infrastructure needs, the position of HIV/ AIDS care on the local political agenda, and the physician-centered organization of the work process. The study also highlighted the interlocutors' agency in the production of strategies to deal with these difficulties. The study further emphasized the local dimension as a social marker of difference that modeled the interlocutors' experiences, where the health policy's guidelines and principles are performed by health professionals, administrators, and users, comprising diverse material forms.

HIV; Acquired Immunodeficiency Syndrome; Health Personnel; Rural Health Services

\section{Resumen}

Este estudio etnográfico tuvo como objetivo comprender la experiencia de profesionales de salud, que trabajan en un Servicio de Atención Especializada en VIH/SIDA en un contexto de área remota, en el nordeste brasileño. Para la recogida de datos, se utilizaron técnicas observación participante y entrevista semiestructurada con siete profesionales que componian el equipo del servicio estudiado. Mediante la técnica de codificación temática, se obtuvieron tres categorías: "yo no sabía ni lo que era": aspectos de lo que supone convertirse en un profesional especializado en VIH/SIDA; "está todo el mundo allí medio escondido": estrategias de enfrentamiento a la (in)visibilidad del estatus serológico; $y$ "la gente vive sobre una cuerda floja": experiencias en el proceso de trabajo. El aspecto más relevante de este estudio se refiere a la invisibilidad institucional del servicio, como reflejo de la actual red de atención al SIDA en Brasil. Los resultados señalaron algunas dificultades propias de servicios localizados en áreas remotas, resaltándose la inexperiencia de los profesionales y su agravamiento por la carencia de formación permanente; necesidad de infraestructuras; el lugar de las acciones de salud en relación con VIH/SIDA dentro de la agenda politica local, y la centralidad del quehacer médico en la organización del proceso de trabajo. Se destaca, no obstante, la voluntad de los interlocutores para generar estrategias que enfrenten esas dificultades. Este estudio es relevante al resaltar la dimensión local, como un marcador social de las diferencias que modelaban las experiencias de los interlocutores, pues es alli donde se llevan a cabo las directrices y los principios de politica de salud por parte de profesionales, gestores $y$ usuarios formando materialidades diversas.

VIH; Sindrome de Inmunodeficiencia Adquirida; Personal de Salud; Servicios de Salus Rural

Recebido em 28/Mar/2018

Versão final reapresentada em 23/Jun/2018

Aprovado em 19/Jul/2018 